\title{
CIDADES VERDES: CONTRIBUIÇÕES PARA O DEBATE SOBRE RIOS URBANOS E CORREDORES VERDES
}

\author{
Eloisa Carvalho de Araujo ${ }^{1}$
}

Natália Fernandes Ribeiro ${ }^{2}$

\begin{abstract}
RESUMO
O presente artigo assume o caráter de um ensaio voltado a uma discussão técnica e científica a partir do diálogo entre os temas da Requalificação Ambiental Urbana e da Infraestrutura Verde, integrado a um processo de pesquisa em desenvolvimento. A investigação surge em um contexto onde cidades brasileiras começam a se destacar e a se comprometer com as metas para alcançarem o status de cidades verdes e, tem como foco os impactos gerados por ações impressas a partir das intervenções urbanísticas de requalificação e transformação de ambientes urbanos na qualidade dos espaços e de vida da população. Em um contexto metropolitano, tem na cidade do Rio de Janeiro, em especial sua zona oeste, seu recorte espacial.
\end{abstract}

PALAVRAS-CHAVE: Requalificação Ambiental Urbana. Infraestrutura Verde. Periferia.

\section{GREEN CITIES: CONTRIBUTIONS TO THE DEBATE ON RIVERS AND URBAN GREEN CORRIDORS}

\begin{abstract}
This article assumes the character of a test towards the technical and scientific discussion through dialogue between the themes of Environmental Urban Renewal and the Green Infrastructure, integrated into a process of research in development. The research appears in a context where Brazilian cities begin to stand out and to commit to the goals to achieve the status of green cities and focuses on the impacts generated by actions printed from the urban interventions of upgrading and transformation urban environments in the quality of spaces and people's livelihood. In a metropolitan context, it has the city of Rio de Janeiro, especially its western part, his spatial area.
\end{abstract}

KEYWORDS: Environmental Urban Renewal . Green infrastructure. Periphery.

1 Profa. Doutora do Programa de Pós-graduação em Arquitetura e Urbanismo e da Escola de Arquitetura e Urbanismo da Universidade Federal Fluminense - EAU/UFF. eloisa.araujo@gmail.com

${ }^{2}$ Mestranda do Programa de Pós Graduação em Arquitetura e Urbanismo (PPGAU), Universidade Federal Fluminense.nataliaferibeiro@gmail.com. 


\title{
CIUDADES VERDES: APORTACIONES AL DEBATE SOBRE RÍOS Y CORREDORES VERDES URBANAS
}

\begin{abstract}
RESUMEN
En este artículo se asume el carácter de una prueba de vuelta en una discusión técnica y científica a través del diálogo entre los temas de Medio Ambiente de Renovación Urbana y la Infraestructura Verde, integrado en un proceso de investigación en el desarrollo. La investigación aparece en un contexto en que las ciudades brasileñas comienzan a destacar y se comprometa con los objetivos de lograr el estado de las ciudades verdes y se centra en los impactos generados por las acciones impresos de las intervenciones urbanas de modernización y transformación de los entornos urbanos la calidad de las habitaciones y la vida del pueblo. En un contexto metropolitano, tiene la ciudad de Río de Janeiro , especialmente su parte occidental, el área espacial.
\end{abstract}

PALABRAS CLAVE: Medio Ambiente Urbano de Renovación . Infraestructura Verde. Periferia.

\section{INTRODUÇÃO}

O presente artigo, como um ensaio, está voltado a uma discussão técnica e científica a partir do diálogo entre os temas da Requalificação Ambiental Urbana e da Infraestrutura Verde. Integrado a um processo de pesquisa em desenvolvimento ${ }^{3}$, surge em um contexto onde cidades brasileiras começam a se destacar e a se comprometer com metas para alcançarem o status de Cidades Verdes. Tem como foco os impactos gerados por ações impressas a partir das intervenções urbanísticas de requalificação e transformação de ambientes urbanos com impacto na qualidade de vida da população.

O estudo da Economist Intelligence Unit (EIU) ${ }^{4}$, patrocinado pela Siemens, ressalta que a América Latina é a região mais urbanizada do mundo em desenvolvimento. O percentual de população que vive em cidades latinoamericanas, atualmente no patamar de $81 \%$, deverá crescer mais ainda, o que é preocupante. O referido estudo aponta que até 2030, deverá chegar a $86 \%$. Este

\footnotetext{
${ }^{3}$ Insere-se no Grupo de Pesquisa do CNPq - Cidade, Processos de Urbanização e Ambiente.

${ }^{4}$ Trata-se do índice de Cidades Verdes da América Latina, desenvolvido pelo Economist Intelligence Unit (EIU), patrocinado pela Siemens, que buscou medir e avaliar o desempenho ambiental das 17 maiores cidades latinoamericanas.
} 
vertiginoso crescimento acaba por gerar efeitos econômicos, políticos, sociais e ambientais.

A pressão exercida pela expansão urbana, invariavelmente causa impacto na infraestrutura existente, com implicações para as edificações, transporte público, sistema viário, qualidade e acesso à água, coleta de resíduos e saneamento básico. Nessa perspectiva a cidade de Curitiba apresenta, no estudo acima referenciado, alto desempenho, por naturalmente ter exercido a capacidade de enfrentar, de forma holística a temática do meio ambiente. Ainda segundo a pesquisa, na década de 1980, o plano urbano desta cidade buscou envolver iniciativas integradas visando tratar, sobretudo, questões como a criação de áreas verdes, reciclagem e manejo de resíduos e saneamento básico, além de questões relacionadas aos transportes públicos, com repercussão, de forma positiva, na qualidade do ar. Este planejamento integrado permitiu um bom desempenho, da referida cidade, na área ambiental.

Entretanto, a capital paranaense conta hoje com a companhia de outras cidades em busca de um ambiente mais equilibrado, limpo e agradável. JUBÉ RIBEIRO (2010), ao promover o debate sobre a produção do espaço urbano a partir de duas vertentes - as condições biofísicas do território e a sociedade - focaliza em Goiânia, por exemplo, uma cidade planejada, a leitura de como o meio ambiente, os projetos e as pessoas em sua vivência ordinária podem compor uma nova paisagem. Para a autora, na maioria das cidades latino-americanas verifica-se o desequilíbrio entre concentração humana e a capacidade de oferecer serviços minimamente adequados, gerando pressão indiscriminada sobre terras periféricas, sem planejamento, colocando em risco recursos naturais e paisagens, agravando os problemas ambientais.

É a partir dos anos 2000, que ações estratégicas de infraestrutura verde vêm sendo promovidas. E, segundo a autora, trata-se de uma nova postura de projeto para o meio urbano frente aos problemas ambientais, objetivando o equilíbrio entre as condições biofísicas e a sociedade, tendo como foco os espaços abertos em escala regional. Em 2005 acontece no Rio de Janeiro o 1ํ Seminário Nacional sobre 
transformações que os sistemas ambientais têm sofrido ao longo dos últimos séculos, tendo também como foco a qualidade ambiental urbana como importante subsídio ao planejamento das cidades.

Com esse entendimento o presente artigo objetiva gerar reflexões sobre questões associadas a rios urbanos e corredores verdes em faixas marginais num contexto de regiões periféricas, a partir do recorte espacial privilegiado no estudo. Também, sob a perspectiva de estabelecer diálogo entre os temas de requalificação ambiental urbana e infraestrutura verde, pretende sensibilizar para a concepção de iniciativas de recuperação de áreas degradadas, ao valorizar a importância da atividade paisagística em rios, em um contexto de áreas periféricas.

Tais ações, a nosso ver, podem ser consideradas como diretriz de sustentabilidade, articuladora de políticas públicas, de saneamento ambiental, educação e cultura.

\section{MÉTODOS DE ANÁLISE}

A proposta em desenvolvimento, decorrente de uma revisão bibliográfica, condicionada ao processo investigativo, apoia-se na exposição de contribuições de autores que abordam os temas da requalificação ambiental urbana e infraestrutura verde na perspectiva das práticas nas cidades contemporâneas.

Posteriormente o trabalho será desenvolvido, sob o método da Ecologia da Paisagem $^{8}$, por entendermos que este favorece a identificação das interações entre os fatores no ecossistema de uma dada paisagem, algumas considerações sobre o tema. Esse método de análise pretende, ao valorizar o trabalho empírico, identificar e classificar as áreas de estudo, quanto às unidades de paisagem, problemas e potencialidades, a partir de um recorte espacial e temporal a serem privilegiados no estudo. Desse método, deriva, segundo HERZOG \& ROSA (2010) o conceito de

\footnotetext{
${ }^{8}$ Adotamos, no presente artigo, conceito de Ecologia da Paisagem trabalhado por METZGER (2010) que o define como uma visão integradora de paisagem como um mosaico heterogêneo formado por unidades interativas, sendo esta heterogeneidade existente para pelo menos um fator, segundo um observador e numa determinada escala de observação. Isto é, centrada, por um lado, nas interações do homem com seu ambiente, e, por outro, preocupada em como a heterogeneidade se expressa espacialmente.
} 
FRANCO,1997; FORMAN; GODRON, 1986) apontam no sentido da sensibilização, percepção e compreensão do ambiente. Mas segundo SANDEVILLE Jr. (2005), é na escala do lugar, que se desenvolve, com base na proposição da paisagem como experiência partilhada e socialmente construída, tendo como foco estudos de campo e sua correlação com processos estruturais do espaço social, a capacidade de percepção da realidade vivenciada. Por exemplo, a percepção do ambiente poluído, que necessita fugir das ameaças da degradação e que está associada a um problema que requer solução, passa a ser uma meta de projeto.

No debate das cidades verdes é necessário ressaltar a combinação entre as políticas, a educação pública e os projetos locais, que incorporam, desde funções naturais na infraestrutura existente, o aprimoramento e o fortalecimento de bacias hidrográficas, como também a criação de espaços livres atrativos para a vida social nos bairros urbanos, entre outros tantos aspectos.

Das iniciativas brasileiras quanto às intervenções em cursos d'água, remonta ao início do século $X X$ a regularização do Rio Tietê, pelo engenheiro sanitarista Francisco Rodrigues Saturnino de Brito. O projeto, segundo ROSA (2013), embora não tenha se tornado realidade, incluía desde lagos e canais, os quais dariam conta de escoar as águas, como também, um parque linear nas várzeas do rio. 
paisagem em conformidade com as necessidades e conhecimentos contemporâneos.

No Brasil, a trajetória para recuperar a qualidade ambiental dos cursos de água urbanos envolve, sobretudo, a associação de políticas urbanas e investimentos. Segundo MORETTI (2000), "renaturalização ou revitalização", não seria somente o processo de trazer de volta as condições mais naturais e originais possíveis, dos rios, mas também a necessidade de promover a integração de distintos setores da administração pública que precisam atuar de forma integrada no enfrentamento dos problemas relacionados.

\section{RESULTADOS NO ÂMBITO DA ÁREA DE ESTUDO - REFLEXÕES EM CURSO}

A investigação, em desenvolvimento, tem na cidade do Rio de Janeiro, em especial sua zona oeste, seu recorte espacial. A cidade cresceu e se desenvolveu a base de projetos e planos de embelezamento e melhoramento da região central com descaso para os bairros suburbanos. Todavia, podemos observar que o projeto ferroviário foi o que permitiu o deslocamento da população das zonas periféricas do município e sua integração com o centro da cidade, propiciando o crescimento dos bairros mais afastados.

Os bairros da Zona Oeste começaram a ser povoados com a finalização do ramal ferroviário Santa Cruz no final do século XIX. Mas o incremento populacional veio associado ao prolongamento da Avenida Brasil até o bairro Bangu, no final da década de 1950. Posteriormente, na década de 1990, com a construção do projeto da Linha Amarela - via expressa que liga a região da Zona Norte do município com a Barra da Tijuca, a tendência demográfica foi de crescimento. ${ }^{10}$ Este crescimento teve como resultado recente, obras realizadas para os jogos Pan Americanos e atualmente para os jogos Olímpicos, implicando em momento de grande

\footnotetext{
${ }^{10}$ A região da Zona Oeste do Rio teria crescido em $150 \%$ seu contingente populacional entre os anos 2000 e 2010Dos dez bairros cariocas mais populosos em 2010, sete ficam na zona oeste: Campo Grande (328,3 mil), Bangu (243,1 mil), Santa Cruz (217,3 mil), Realengo (180,1 mil), Jacarepaguá $(157,3$ mil), Barra da Tijuca (135,9mil) e Guaratiba $(110$ mil). Ver em: http://g1.globo.com/brasi/noticia/2011/07/ibge-bairros-na-zona-oeste-do-rio-crescem-ate-150.html. Acesso em 27 de maio de 2015.
} 


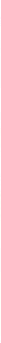

especulação imobiliária. Mas a região em que se insere o recorte espacial de estudo se refere a área de planejamento AP5 ${ }^{11}$, do Plano Diretor ${ }^{12}$ (Figura 4).

Figura 04: Área de Estudo - Áreas de Proteção

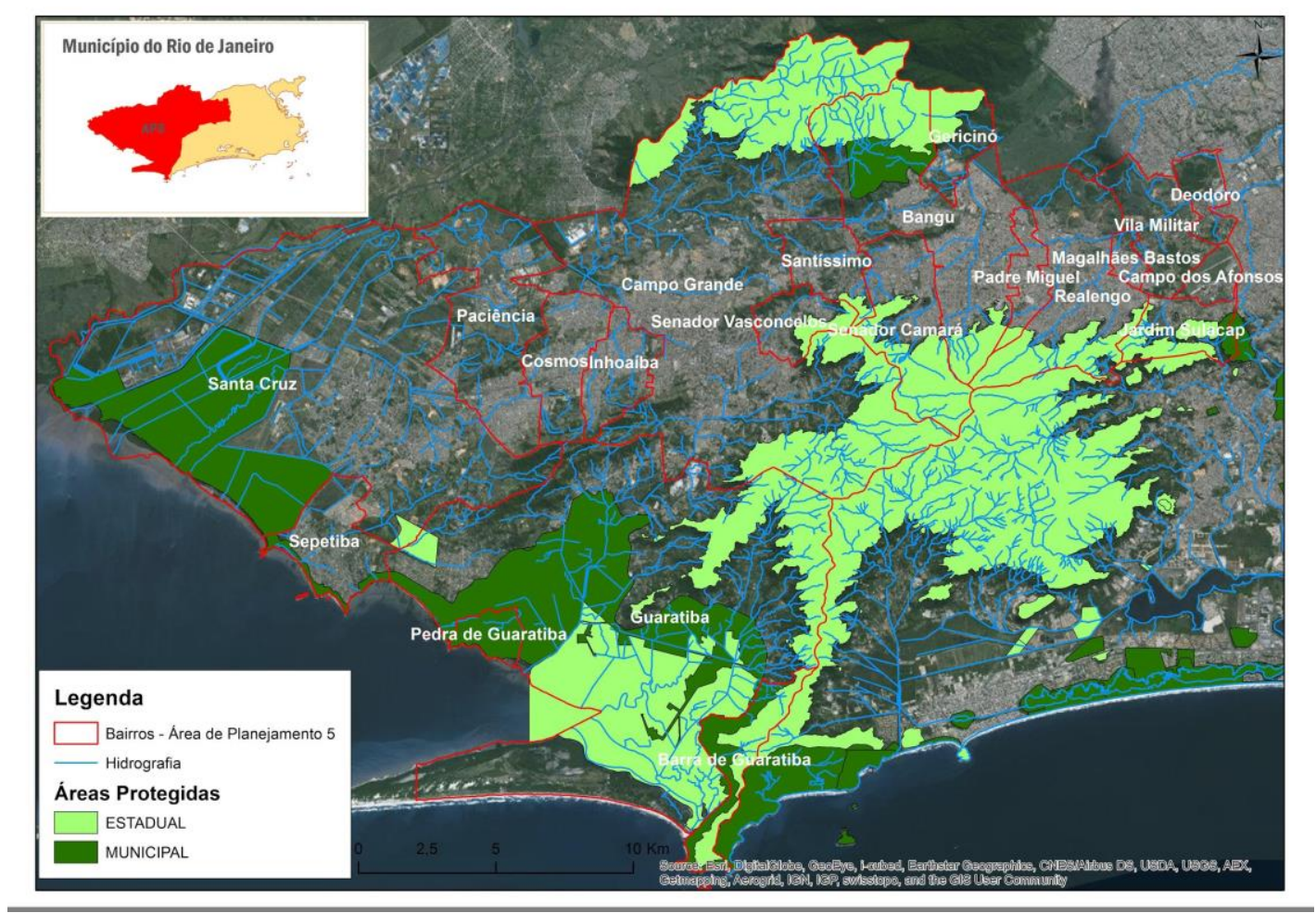

Fonte: Elaboração própria a partir de imagem google

Cercada pelo Maciço da Pedra Branca (Parque Estadual Maciço da Pedra Branca) e o Maciço do Mendanha (Parque Natural Municipal do Mendanha), é uma área que também compreende grande parte da bacia hidrográfica do Rio Guandu, região RJ1 no Comitê Guandu de Bacias Hidrográficas do Rio de Janeiro (Figura 5). Onde se verifica um híbrido de áreas verdes e de vegetação mais densa e selvagem, culminando em um ambiente de natureza preservada.

\footnotetext{
${ }^{11}$ A AP5 é composta por cinco Regiões Administrativas, conforme segue: Bangu (RA XVII), Realengo (RA XXXIII), Campo Grande (RA XXVIII), Guaratiba (RA XXVI) e Santa Cruz (RA XIX).

12 Plano Diretor de Desenvolvimento Urbano Sustentável do Rio de Janeiro. Aprovado pela Lei complementar № 111 de 2011. Ver em: http://www.rio.rj.gov.br/dlstatic/10112/3372233/DLFE262093.pdf/LEICOMPLEMENTARN1.1.1.DE0.1.DEDEZEMBRODE2.0.1.1..pdf. Acesso em : 24 de maio de 2015.
} 


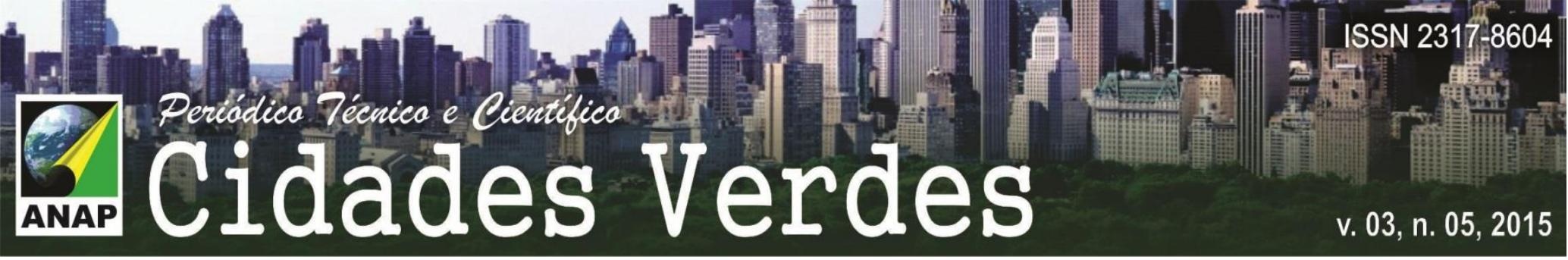

Figura 05: Elementos do relevo em destaque.

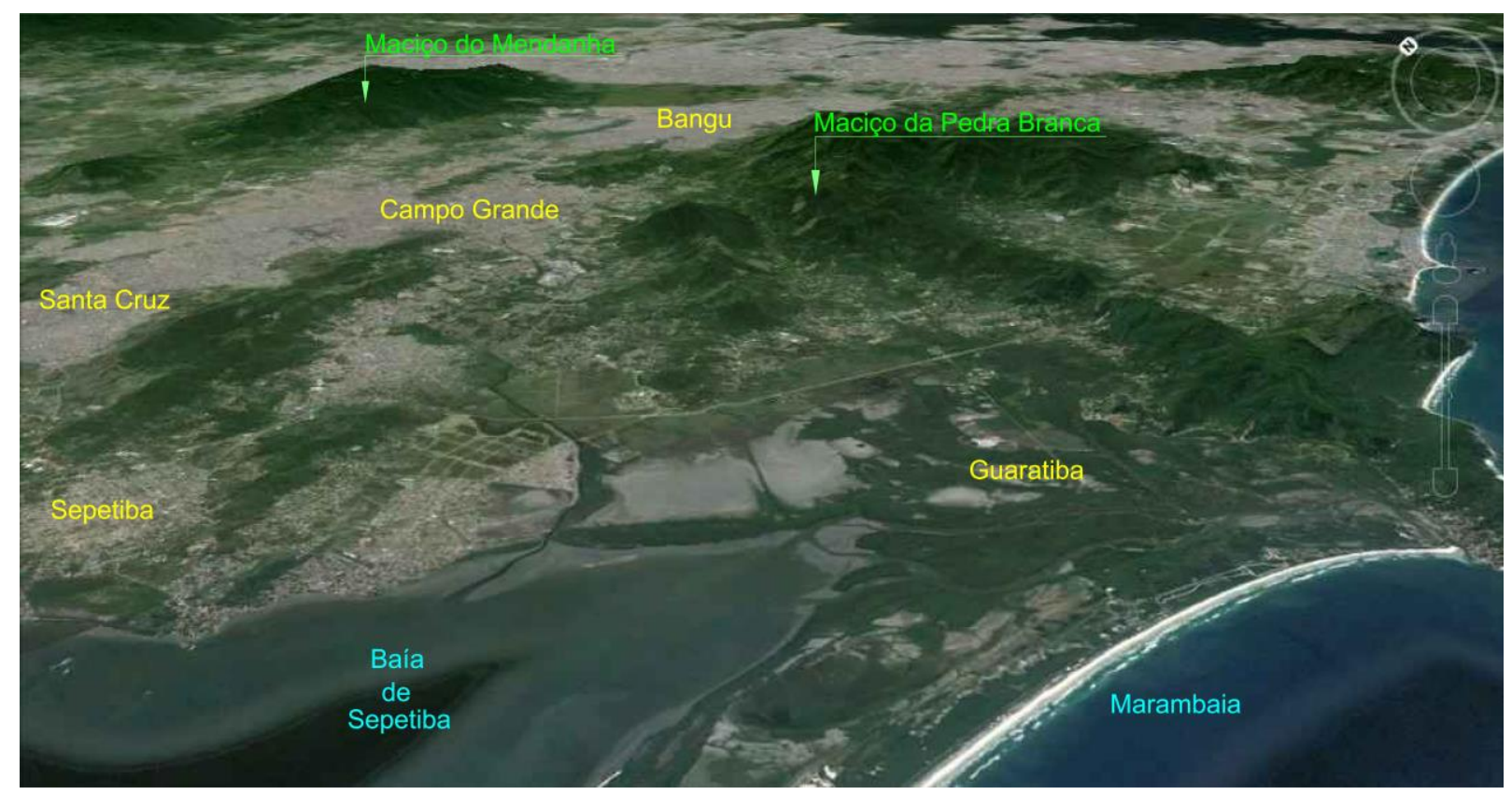

Fonte: Elaboração própria a partir de imagem Google.

Se por um lado podemos ressaltar as características físicas e a hidrologia da região. Por outro, a existência de grande quantidade de rios, a maioria já canalizados ou modificados em valões a céu aberto (Figuras 06 e 07), convive com a presença de lixo e esgoto nas águas urbanas.

Nesse aspecto HERZOG (2009), a partir de experiência na região, em especial no bairro de Guaratiba, ressalta a valorização da relação da população local com a paisagem, no sentido de evitar a degradação dos ecossistemas naturais. 


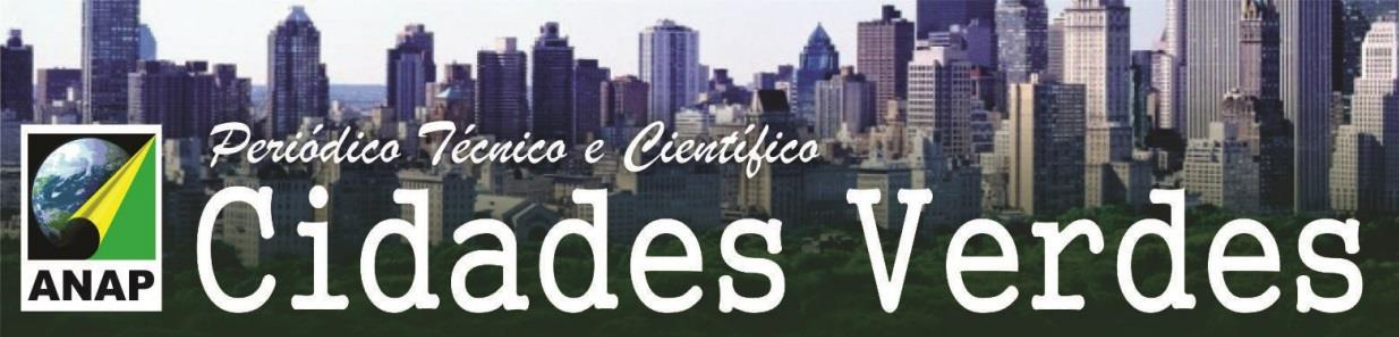

MORETTI, Ricardo de Souza. Urbanização de terrenos situados a rios, córregos e fundo de vale - conflitos e propostas. Campinas [SP]: PUC-Campinas, 2000.

PREFEITURA DA CIDADE DO RIO DE JANEIRO. Plano Diretor de Desenvolvimento Urbano Sustentável do Rio de Janeiro. Lei Complementar № 111 de 2011. Ver em : http://www.rio.rj.gov.br/dlstatic/10112/3372233/DLFE262093.pdf/LEICOMPLEMENTARN1.1.1.DE0.1.DEDEZEMBRODE2.0.1.1..pdf. Acesso em: 24 de maio de 2015.

PRESIDÊNCIA DA REPÚBLICA. Código Florestal - Lei no 12.651/2012. Ver: www.planalto.gov.br/ccivil_03/_ato2011-2014/2012/lei//12651.htm. Acesso em 12 de maio de 2015.

RIBEIRO FRANCO, Maria de Assunção. Infraestrutura Verde em São Paulo: o caso do Corredor Verde Ibirapuera-Villa Lobos. In:

http://www.revistas.usp.br/revistalabverde/article/viewFile/61284/64219. Acesso em 08 de maio de 2015.

RIBEIRO FRANCO, Maria de Assunção. Planejamento Ambiental para a cidade sustentável. São Paulo: Annablume/Fapesp, 1997.

ROSA, Giovanni Santa. Do outro lado do rio: retificações, canalizações e projetos abandonados dos rios de São Paulo, 2013. Ver em: http://gizmodo.uol.com.br/do-outro-lado-do-rio-segunda-parte/. Acesso em 23 de maio de 2015.

SANDEVILLE JR. Paisagem. Revista Paisagem e Ambiente, v.20. São Paulo, 2005.

SIEMENS. Estudo da "Economist Intelligence Unit (EIU)". Índice de Cidades Verdes da América Latina, 2010. Ver em:

http://www.siemens.com/entry/cc/features/greencityindex_international/br/pt/pdf/report_latam_pt_new. pdf. Acesso em 08 de maio de 2015. 